\title{
Coloration and Multi-Functionalization of Polypropylene Fabrics with Selenium Nanoparticles
}

\author{
Tarek AbouElmaaty ${ }^{1, *(\mathbb{D}}$, Shereen A. Abdeldayem ${ }^{2}{ }^{\mathbb{D}}$, Shaimaa M. Ramadan ${ }^{2}$, Khaled Sayed-Ahmed ${ }^{3}$ \\ and Maria Rosaria Plutino ${ }^{4}$ (D) \\ 1 Department of Material Art, Galala University, Galala 43713, Egypt \\ 2 Department of Textile Printing, Dyeing and Finishing, Faculty of Applied Arts, Damietta University, \\ Damietta 34512, Egypt; shereen.abdeldayem.82@gmail.com (S.A.A.); designer_shemo@yahoo.com (S.M.R.) \\ 3 Department of Agricultural Chemistry, Faculty of Agriculture, Damietta University, Damietta 34512, Egypt; \\ dr_khaled@yahoo.com \\ 4 Stituto per lo Studio dei Materiali Nanostrutturati, Consiglio Nazionale delle Ricerche, Vill. S. Agata, \\ 98166 Messina, Italy; plutino@pa.ismn.cnr.it \\ * Correspondence: tasaid@gu.edu.eg
}

check for updates

Citation: AbouElmaaty, T.; Abdeldayem, S.A.; Ramadan, S.M.; Sayed-Ahmed, K.; Plutino, M.R.

Coloration and

Multi-Functionalization of Polypropylene Fabrics with Selenium Nanoparticles. Polymers 2021, 13, 2483. https://doi.org/10.3390/ polym13152483

Academic Editor: Andrea Zille

Received: 7 July 2021

Accepted: 23 July 2021

Published: 28 July 2021

Publisher's Note: MDPI stays neutral with regard to jurisdictional claims in published maps and institutional affiliations.

Copyright: (c) 2021 by the authors. Licensee MDPI, Basel, Switzerland. This article is an open access article distributed under the terms and conditions of the Creative Commons Attribution (CC BY) license (https:/ / creativecommons.org/licenses/by/ $4.0 /)$.

\begin{abstract}
In this study, we developed a new approach for depositing selenium nanoparticles (SeNPs) into polypropylene (PP) fabrics via a one-step process under hydrothermal conditions by using an IR-dyeing machine to incorporate several functionalities, mainly coloration, antibacterial activity and ultraviolet (UV) protection. The formation, size distribution, and dispersion of the SeNPs were determined using X-ray diffraction (XRD), ultraviolet-visible (UV/Vis), transmission electron microscopy (TEM) and the color strength, fastness, antibacterial properties, and UV protection of the treated fabrics were also explored. The UV-Vis spectra and TEM analysis confirmed the synthesis of spherical well-dispersed SeNPs and the XRD analysis showed the successful deposition of SeNPs into PP fabrics. The obtained results demonstrate that the SeNPs-PP fabrics is accompanied by a noticeable enhancement in measurements of color strength, fastness, and UV-protection factor (UPF), as well as excellent antibacterial activity. Viability studies showed that SeNPs-PP fabrics are non-toxic against wi-38cell line. In addition, the treated SeNPs-PP fabrics showed an increase in conductivity. The obtained multifunctional fabrics are promising for many industrial applications such as the new generation of curtains, medical fabrics, and even automotive interior parts.
\end{abstract}

Keywords: selenium nanoparticles; polypropylene; coloration; antibacterial; conductivity; UV protection

\section{Introduction}

Numerous washable or disposable healthcare and hygiene textile products are used in hospitals either for the protection of staff and patients (drapes, beddings, masks, uniforms, wound dressings, bandaging materials, etc.) [1]. Due to the large surface areas, textiles have superior abilities to retain warmth, moisture, and nutrients from spillages and exudates, making them ideal substrates for microorganisms to grow on [2]. Some studies have suggested that healthcare textiles can act as reservoirs and vehicles for the spread of microorganisms in hospitals [3]. With the development of nanotechnology, some inorganic nanoparticles (NPs), such as silver, copper, and zinc, have been identified as promising candidates in combating pathogenic microorganisms [4-9]. Nanotechnology-driven therapies with metal and metal oxide nanoparticles (NPs) are emerging as a promising alternative to antibiotics. The high reactivity of these NPs, due to large surface-to-volume ratio, results in intrinsic targeted antimicrobial efficiency even when they are applied in small amounts [10]. Proven activity of metal and metal oxide NPs against wide range of microorganisms including bacteria, fungi, viruses, and other eukaryotic microorganisms [11] was inspiring for researchers to immobilize them onto textiles [12-15]. Selenium nanoparticles (SeNPs) has become the new research target because they are found to possess excellent 
bioavailability, low toxicity, and contribute to a wide spectrum of health promotion, as well as disease prevention and treatment activities [16]. Biswas et al. [17] prepared silver or selenium nanoparticles on polymeric scaffolds and compared the cytotoxicity of the scaffolds towards mouse fibroblasts using an indirect contact method; the results indicated that the Ag-loaded scaffolds showed high cytotoxicity, while the Se-loaded scaffolds were not toxic to the cells. The low cytotoxicity of SeNPs indicates the great potential for use in biomedical applications [3]. The research on SeNPs as antimicrobial agents is still limited. Several studies have pointed out the ability of SeNPs to exhibit anticancer [18], antioxidant [19], antibacterial and anti-biofilm [20] properties. So far, remarkable antimicrobial activity of these nanoparticles has been evidenced against pathogenic bacteria, fungi, and yeasts [21-23], which inspired researchers to immobilize them onto textiles.

Polypropylene (PP) fabric has excellent physical and mechanical properties [24]. It is a hydrophobic fabric, and several surface modification techniques are adopted to improve wetting, adhesion to polymer surfaces by introduction of a variety of polar groups [25-27]. PP advantages include a great supply, good process, low energy demand, low cost and high chemical stability [28]. There is a great demand for antibacterial PP fabric to be used in different medical applications $[29,30]$. To our knowledge, there are no reports dealing with coloring PP by using SeNPs without any additives and studying the antibacterial and UV-protection properties, cytotoxicity, and electrical conductivity of the resulted SeNPs-PP fabrics. In this study, SeNPs are prepared in one step process under a simple redox system based on the method mentioned by Abou Elmaaty et al. [31] followed by application of the SeNPs to PP fabric in one-step process under hydrothermal conditions. The characteristics of SeNPs in solution phase were studied by UV-visible spectrophotometer (UV/Vis), transmission electron microscopy (TEM) and X-ray diffraction (XRD). Moreover, scanning electron microscopy (SEM), colour characteristics and antibacterial and UV-protection properties, cytotoxicity and electrical conductivity of the SeNPs-PP fabrics were also evaluated. In summary, we developed a simple, green, and feasible route to produce green coloration of PP-based fabric for multifunctional applications. The low cytotoxicity of SeNPs and antibacterial properties indicates their great potential for use in biomedical applications.

\section{Materials and Methods}

\subsection{Fabric and Chemicals}

Polypropylene fabric (100\%) was supplied by Shikisen-sha Company (Osaka, Japan) with crystallinity (50.6\%), melting enthalpy $(105.8 \mathrm{~J} / \mathrm{g})$ [32], density $(0.91 \mathrm{~g} / \mathrm{c.c})$, moisture regain $(0 \%)$ and tenacity $(3.5-8.0 \mathrm{~g} / \mathrm{den})$. Sodium hydrogen selenite, ascorbic acid and polyvinylpyrrolidone (PVP) were purchased from LobaChemie, India. Other chemicals were commercial grade.

\subsection{Green Synthesis of Selenium Nanoparticles (SeNPs)}

SeNPs were synthesized via a redox reaction based on the method reported by AbouElmaatyet al. with an improved modification [31]. PVP (6g) was dissolved in $100 \mathrm{~mL}$ of sodium hydrogen selenite solution at a concentration of $100 \mathrm{mmol} / \mathrm{L}$. Then, ascorbic acid was added to the mixture at the same concentration and volume ratio of 1:1 under magnetic stirring. The solution changed from colorless to orange to dark orange, indicating the formation of SeNPs [33]. Moreover, the prepared SeNPs colloidal solution at the concentration of $50 \mathrm{mmol} / \mathrm{L}$ was used in this treatment process.

\subsection{Treatment Method}

The PP fabrics were treated using an infrared dyeing machine. The machine includes 12 beakers fixed in a rotating carrying wheel. Heating was obtained by IR, cooling by air, and automation by the microprocessor programmer DC4 F/R. The highest temperature used in this device was $120^{\circ} \mathrm{C}$, the highest rate of heating was $2{ }^{\circ} \mathrm{C}$ per minute, and the highest rate of cooling was $6{ }^{\circ} \mathrm{C}$ per minute. First, a solution of SeNPs $(50 \mathrm{mmol} / \mathrm{L})$ was prepared. The PP fabrics were then immersed in the solution with liquor ratio (LR) 
of 1:50. Next, the device was set at the following treatment temperatures periods. The treatment was performed at different temperatures $\left(70^{\circ} \mathrm{C}, 100^{\circ} \mathrm{C}\right.$ and $\left.120^{\circ} \mathrm{C}\right)$ and different periods $(1,2$ and $3 \mathrm{~h})$. The treated PP fabrics were rinsed with distilled water and allowed to dry at room temperature after the treatment. The obtained fabrics were coded with SeNPs-PP fabrics.

\subsection{Characterization}

2.4.1. Characterization of Selenium Nanoparticles (SeNPs)

Transmission Electron Microscopy (TEM) Analysis

The size and morphology of SeNPs were characterized using JEM-2100 Transmission Electron Microscope with an acceleration voltage of $200 \mathrm{kV}$. A drop of colloidal solution containing SeNPs was dripped onto a carbon coated copper grid and dried at room temperature for TEM analysis.

X-ray Diffraction (XRD) Analysis

X-ray diffraction (XRD) analysis was conducted for synthesized SeNPs and SeNPs-PP fabrics using an X-ray diffractometer system (Bruker D8 ADVANCE, Karlsruhe, Germany). While SeNPs solution was dried at $130^{\circ} \mathrm{C}$ until completely dryness before the XRD analysis.

\section{UV/Vis Spectroscopy Analysis}

SeNPs were further characterized via ultraviolet-visible spectrophotometer (Alpha1860, Indianapolis, IN, USA), and their formation was confirmed by the maximum absorption peak which attributed to their surface plasmon resonance.

\subsubsection{Characterization of Poly Propylene (PP) Fabrics}

Scanning Electron Microscopy (SEM) Analysis

The surface morphology of blank PP and SeNPs-PP fabric was characterized via scanning electron microscope (JEOL JSM-6510LB with field emission gun, Tokyo, Japan). The deposition of SeNPs into PP fabrics was confirmed using surface energy dispersive x-ray (EDX) analysis unit (EDAX AMETEK analyzer) attached to SEM device.

\section{Raman Spectroscopy Analysis}

The types of bonds present in the blank PP and SeNPs-PP fabrics were determined using confocal Raman microscope (Jasco NRS-4500, Tokyo, Japan) which covered the range from 200 to $4000 \mathrm{~cm}^{-1}$. Raman data acquisition and processing were performed using Jasco spectroscopy suite software.

\section{Colorimetric Study}

The colorimetric parameters such as lightness $\left(\mathrm{L}^{*}\right)$, redness-greenness $\left(\mathrm{a}^{*}\right)$, yellownessblueness $\left(b^{*}\right)$ and the color uptake which is expressed as the color strength $(\mathrm{K} / \mathrm{S})$ of the obtained SeNPs-PP fabrics were determined using a spectrophotometer (CM3600A; Konica Minolta, Tokyo, Japan). K/S values were evaluated at the wavelength of maximum absorption $\left(\lambda_{\max }\right)$ of the color's reflectance curve at $390 \mathrm{~nm}$.

\section{Exhaustion of SeNPs into PP Fabric}

The treatment colloidal solution was sampled before and after treatment to measure the exhaustion of SeNPs. The absorbance of the SeNPs colloidal solution was measured using an UV/Vis spectrophotometer (Alpha-1860, Indianapolis, IN, USA).

Physical Properties of SeNPs-PP Fabric

The fastness of the SeNPs-PP fabrics determines the fixation of SeNPs into the fabric. They were determined using AATCC (61-1972), (8-1972), and (16A-1972) [34] tests for washing, rubbing and lightfastness, respectively. The tensile strength tests of the PP and SeNPs-PP fabrics were performed using a universal testing machine (Tinius Olsen EN ISO 
13934-1;1999-model H25KT) [35]. Additionally, the durability to washing was evaluated according to AATCC61(2A)-1996 test [36] after five washing cycles.

\section{Cytotoxicity Test of SeNPs-PP Fabric}

The cytotoxicity of SeNPs-PP fabric was tested against wi-38 cell line. This type of cells is diploid human cell line, including fibroblasts from lung tissue of a 3-month-gestation female fetus. The SeNPs-PP fabric treated at the optimum conditions was sterilized, cut, and plated on the bottom surface of a six-well tissue culture plate. The plate was inoculated with $1 \times 105$ cells $/ \mathrm{mL}(100 \mu \mathrm{L} /$ well $)$ and incubated at $37^{\circ} \mathrm{C}$ for $24 \mathrm{~h}$. Additionally, the growth medium was decanted, and the cell monolayer was washed twice with washing media. Cells were checked for any physical signs of toxicity. Moreover, the tissue was picked up and $20 \mu \mathrm{L}$ 3-(4,5-dimethylthiazol-2-yl)-2,5-diphenyltetrazolium bromide dye (MTT) prepared in phosphate buffer saline (BIO BASIC CANADA INC, Markham, Ontario, Canada) was added to each well at a concentration of $5 \mathrm{mg} / \mathrm{mL}$ and shaken for $5 \mathrm{~min}$. The wells were incubated at $37^{\circ} \mathrm{C}$ and $5 \% \mathrm{CO} 2$ for $1-5 \mathrm{~h}$. After dumping the media, the formazan as MTT metabolic product in the dry plate was resuspended in $200 \mu \mathrm{L}$ dimethyl sulfoxide and shaken for $5 \mathrm{~min}$. Then, the optical density was read at $560 \mathrm{~nm}$, while the background was measured at $620 \mathrm{~nm}$ and subtracted.

Antibacterial Activity

The antibacterial activity of the SeNPs-PP fabric was evaluated using AATCC (1472004) test [37]. Antibacterial tests were carried out against G+ve bacteria (Staphylococcus aureus and Bacillus cereus) as well as G-ve bacteria (Escherichia coli and Pseudomonas aeruginosa) and the growth inhibition zone (mm) was determined.

\section{UV-Protection Properties}

The UV protection factor (UPF) and UV-blocking activities of the SeNPs-PP fabric were determined using Standards Australia and Standards New Zealand (AS/NZS) 4399:1996 tests and UV protection properties were expressed as good, very good, or excellent for UPF values of 15-24, 25-39, and >40, respectively.

Electrical Conductivity Measurement

The electrical conductivity of both the PP and SeNPs-PP fabrics were measured using LRC-bridge (Hioki model 3531zHi Tester, Nagano, Japan).

\section{Results and Discussion}

\subsection{Characterization of SeNPs}

\subsubsection{Transmission Electron Microscopy (TEM) Analysis}

TEM micrographs confirmed the formation of spherical Se-NPs in the range of 31$79 \mathrm{~nm}$. Furthermore, the synthesized SeNPs were well-dispersed with no aggregation and deformation as shown in Figure 1.

Histogram bins are10-nm wide and centered at 35, 45, 55, 65 and $75 \mathrm{~nm}$. All SeNPs with diameters from $40 \mathrm{~nm}$ to $50 \mathrm{~nm}$ were considered to have a size of $45 \mathrm{~nm}$.

Furthermore, TEM was used to examine the adsorption of SeNPs as shown in Figure 1. The TEM images illustrated that SeNPs were sufficiently monodispersed and adsorbed on the SeNPs-PP fabric surface.

\subsubsection{X-ray Diffraction (XRD) Analysis}

XRD confirmed the formation of SeNPs and their deposition into the treated PP fabric based on the crystallinity of SeNPs. As illustrated in Figure 2, SeNPs in a colloidal solution or into the PP fabric surface were highly crystalline. Additionally, the diffraction peaks at $24.28^{\circ}, 29.24^{\circ}, 43.64^{\circ}$ and $64.28^{\circ}$ were corresponding to $100,101,102$ and 210 crystal planes, respectively, based on the JCPDS 86-2246 international database [38]. Moreover, the peaks 
at $13,66,16.56,18.18$, and 25.38 can be observed for PP fabric, corresponding to the planes of (110), (040), (130), and (060), respectively [39].

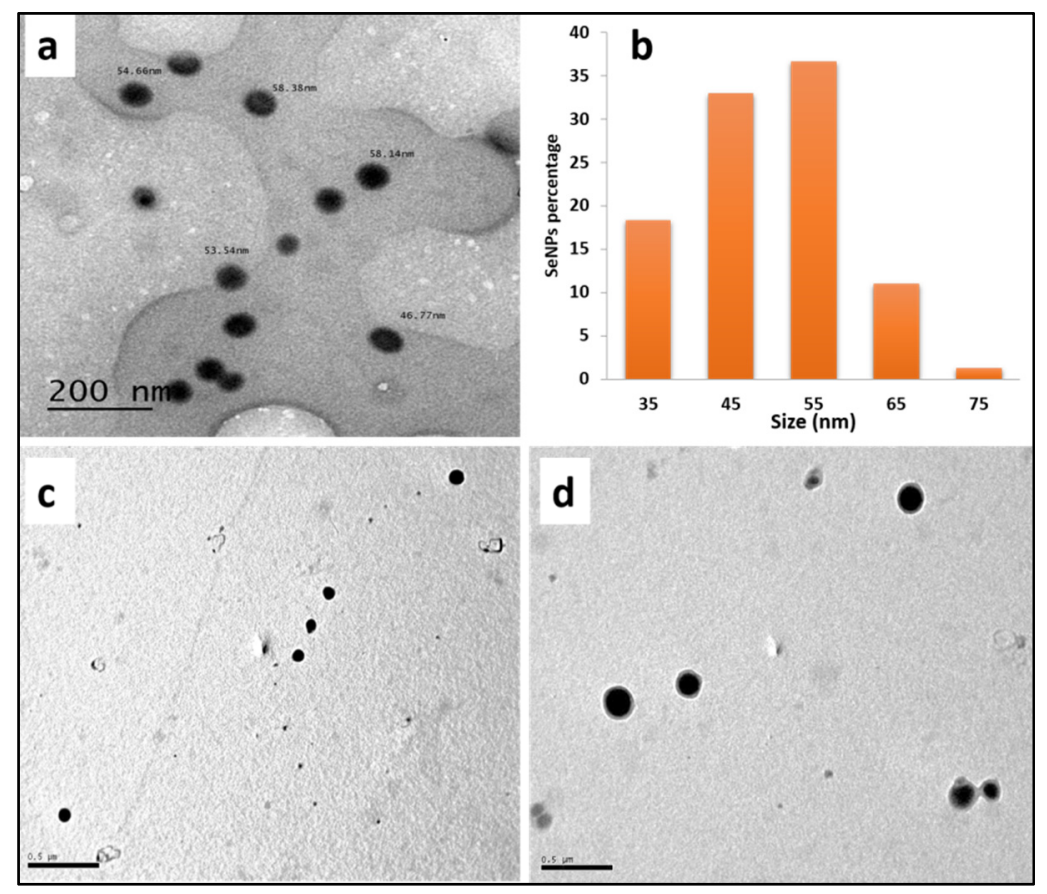

Figure 1. (a) TEM image (b) size distributions histogram of prepared SeNPs, (c,d) SeNPs-PP fabric surface.

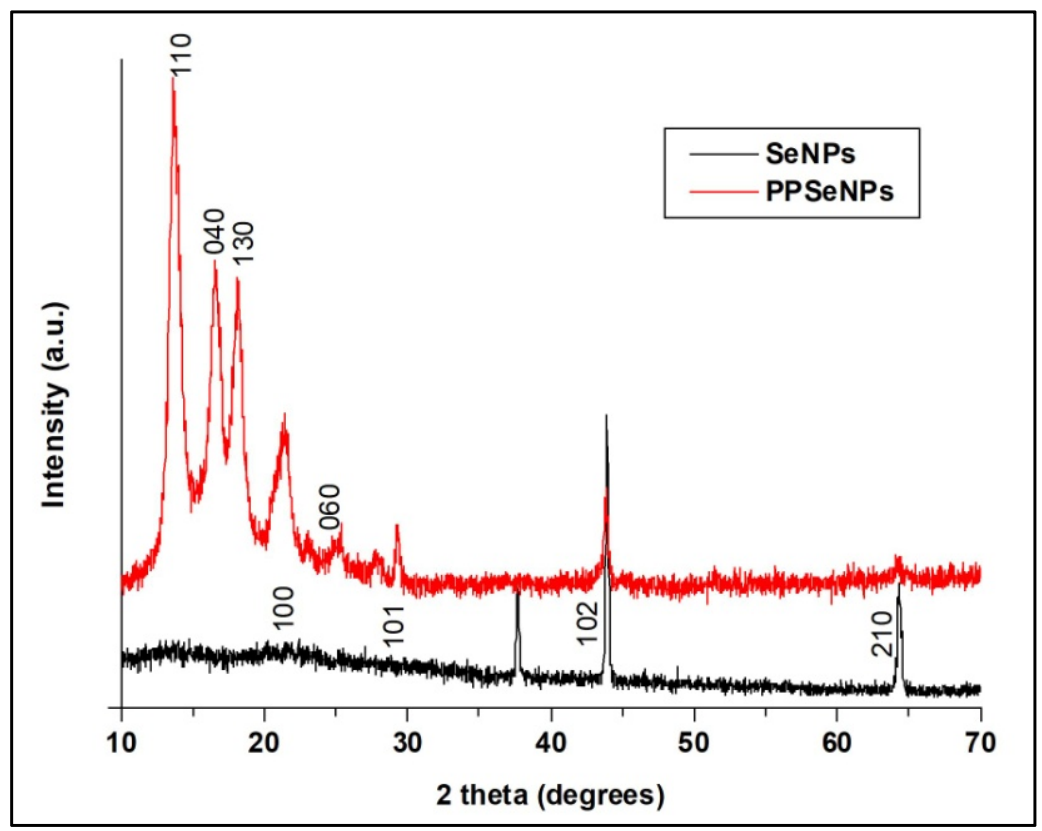

Figure 2. XRD patterns of the prepared SeNPs and SeNPs-PP fabric.

\subsubsection{UV/Vis Spectroscopy Analysis}

The formation of SeNPs was confirmed from the UV/Vis spectra based on their SPRs. The solution changed from colorless to orange to dark orange, indicating the complete reduction of sodium hydrogen selenite to SeNPs [40].

As shown in Figure 3, the SeNPs colloidal solution showed an absorption peak at $263 \mathrm{~nm}$, confirming the formation of the spherical SeNPs [41]. 


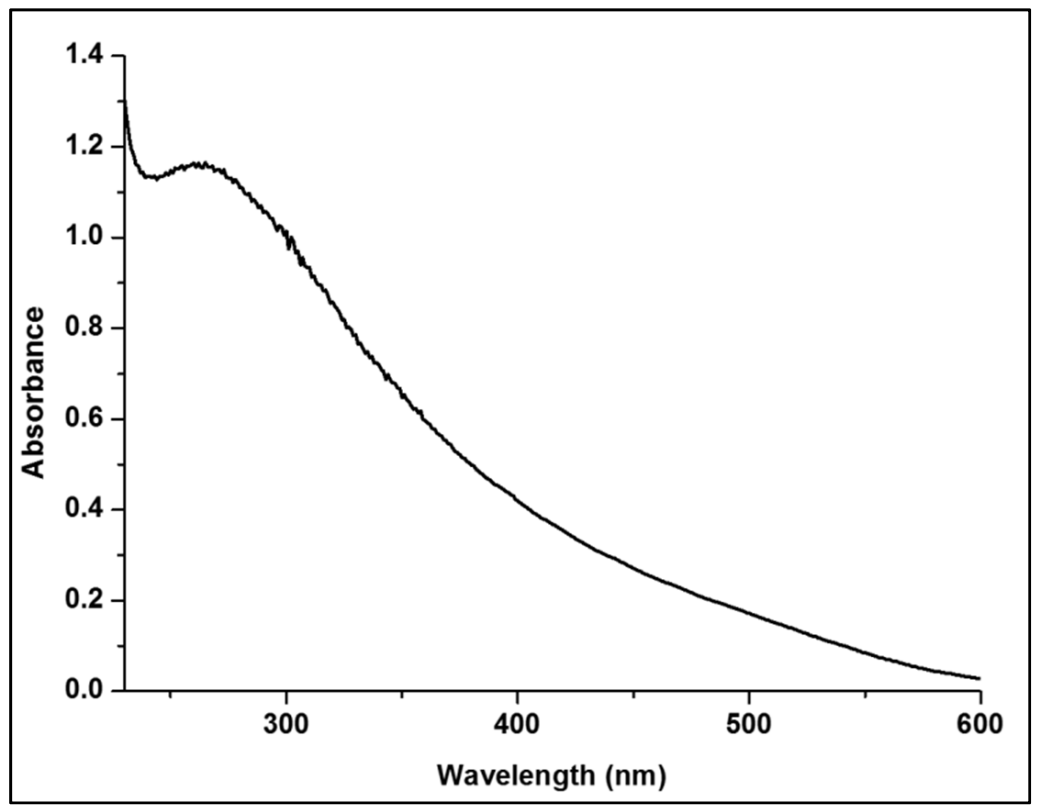

Figure 3. UV/Vis spectra of SeNPs at different concentrations.

\subsection{Characterization of Poly Propylene (PP) Fabrics}

\subsubsection{Scanning Electron Microscopy (SEM) Analysis}

The SEM micrographs of the PP fabric revealed that the surface was clear with clean scales and typical fibrous structure as displayed in Figure 4. On the other hand, the SEM micrographs of the SeNPs-PP fabric show a coated layer of SeNPs into the PP fabric. Additionally, SeNPs were well distributed into the fabric.
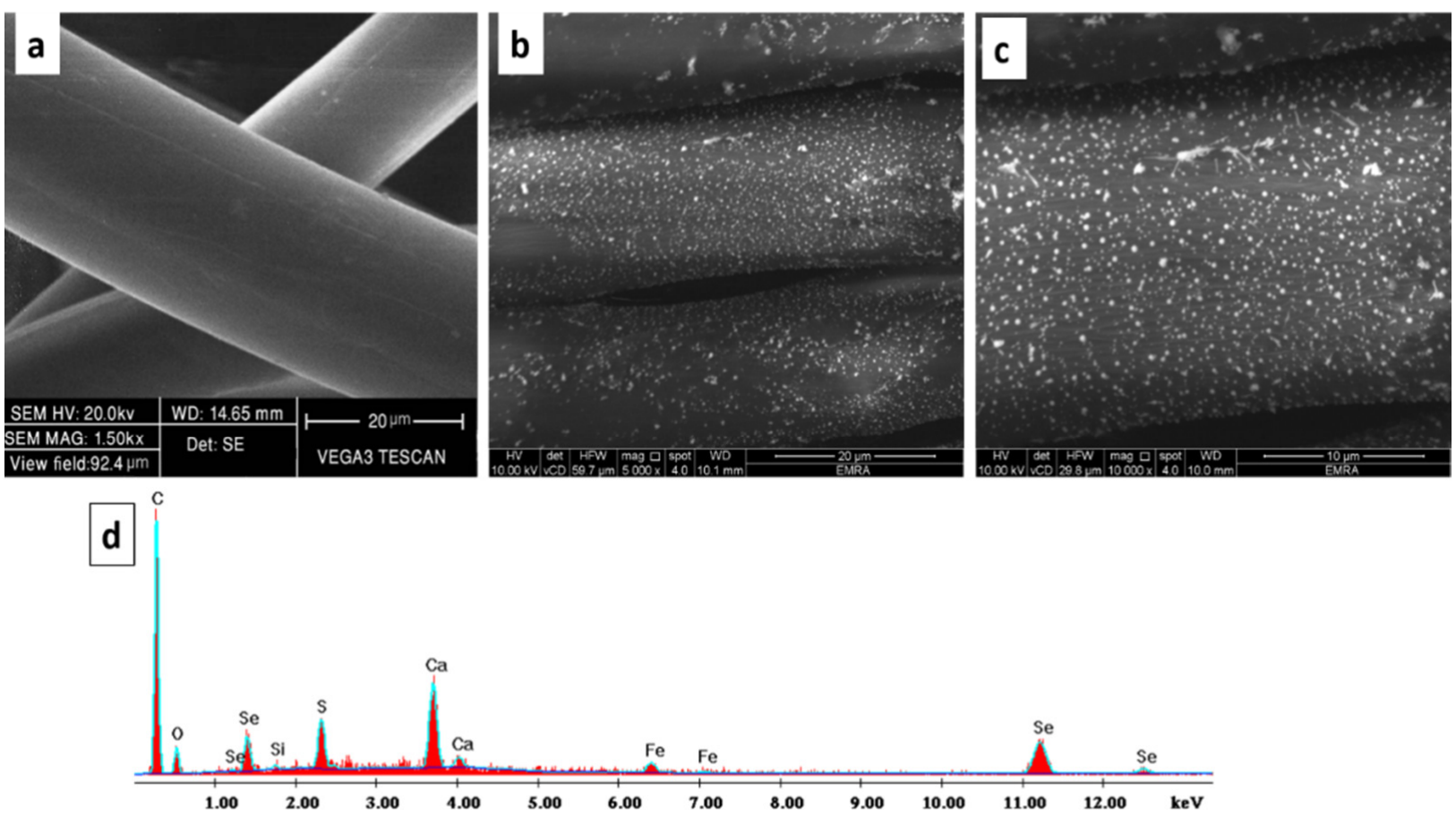

Figure 4. SEM micrographs of (a) the PP fabric, (b,c) SeNPs-PP fabric, (d) EDX analysis of the SeNPs-PP fabric.

The chemical elements found on the surface of the treated PP fabric were analyzed using EDX. The peaks around 1 and $11 \mathrm{Kev}$ are attributed to SeNPs. The carbon and oxygen peaks were belonged to the native PP fabric. However, other elements were monitored at low concentration, such as $\mathrm{Si}, \mathrm{Ca}$, and Fe. Those traces of elements can be attributed to 
using IR-dyeing technique [42]. In addition, the Sulphur element was monitored at low concentration because EDX is an elemental detection technique with a certain small error. Both SEM micrographs and EDX analysis confirmed the deposition of SeNPs into the PP fabric surface as displayed in Figure 4.

\subsubsection{Raman Spectroscopy}

Raman analysis revealed the chemical bonds inside the PP fabric and between the SeNPs and PP surface. This analysis is important to compare the chemical structure of Se-NPs-PP fabric and PP fabric as shown in Figure 5. The peaks at 2960 as well as $2888 \mathrm{~cm}^{-1}$ were corresponding to the asymmetric stretch of methyl group [43]. While the peak at $984 \mathrm{~cm}^{-1}$ was associated with asymmetrical stretching of C-C bond [44]. Furthermore, Raman analysis revealed the presence of SeNPs into the SeNPs-PP fabric. The treated fabric showed an obvious peak at $236 \mathrm{~cm}^{-1}$, corresponding to the symmetric stretching of SeNPs [45]. On the other hand, no peak was observed in this region in the case of PP fabric without SeNPs.
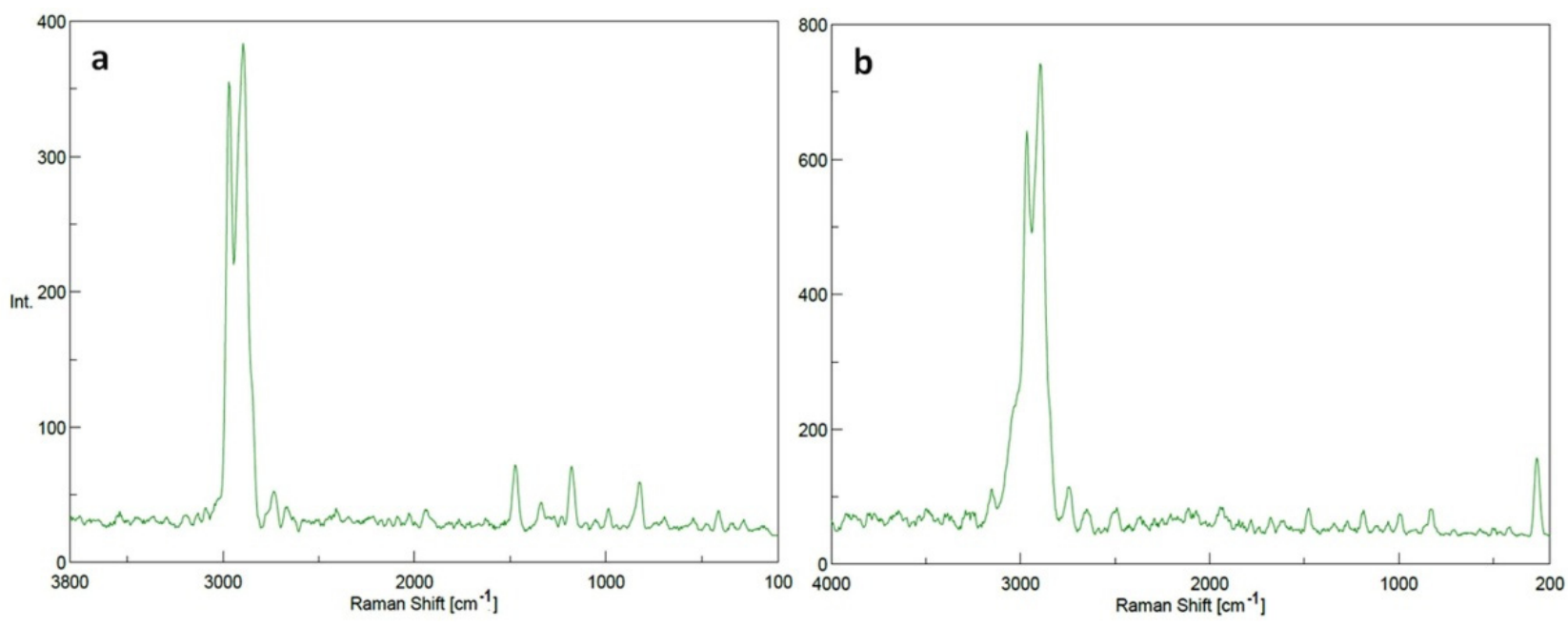

Figure 5. Raman spectrums of (a) PP fabric and (b) SeNPs-PP fabric.

\subsubsection{Colorimetric Study}

The color parameters of the SeNPs-PP fabric were analyzed using a Konica Minolta spectrophotometer (CM-3600A). Figure 6 and Table 1 show the $L^{*} a^{*} b^{*}$ values of the fabric, where $\left(L^{*}\right)$ values represent color lightness, $\left(a^{*}\right)$ is the red/green coordinate, and $\left(b^{*}\right)$ is the yellow/blue coordinate [46]. These values indicated that SeNPs-PP fabric is darker according to the color lightness values $L^{*}$, less red and less yellow according to $a^{*}, b^{*}$ values, respectively.

\section{Effect of Treatment Time on Color Strength (K/S)}

The relationship between the K/S value of the SeNPs-PP fabric and treatment time (1, 2 , and $3 \mathrm{~h}$ ) is shown in Figure 7. Notably, the $K / S$ value of PP fabric treated with SeNPs (concentration of $50 \mathrm{mmole} / \mathrm{L}$, L.R 1:50 and a temperature of $100{ }^{\circ} \mathrm{C}$ ) increased with an increase in the treatment time. The increase in $\mathrm{K} / \mathrm{S}$ value reflected the positive effect that increasing the treatment time had on the uniformity of PP adsorption of the SeNPs, and on the uniformity of the penetration and diffusion of the SeNPs into the fabric; these effects in turn contributed to an increase in the SeNPs uptake by the fabric $[47,48]$; which is indicated by the highest $K / S$ value observed at treatment time of $3 \mathrm{~h}$. 


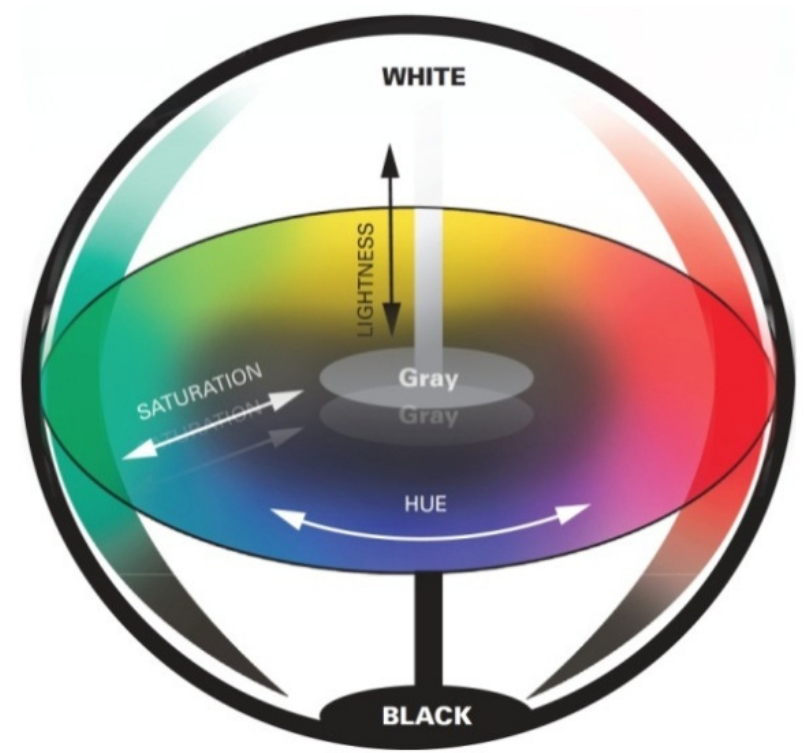

Figure 6. Lab colour space.

Table 1. Optical measurements.

\begin{tabular}{|c|c|c|c|c|c|c|c|}
\hline \multirow{2}{*}{ Type } & \multirow{2}{*}{ Sample } & \multicolumn{6}{|c|}{ Colour Parameters } \\
\hline & & $\mathbf{L}^{*}$ & $a^{*}$ & $\mathbf{b}^{*}$ & $C^{*}$ & $\mathbf{h}$ & $\mathrm{K} / \mathrm{S}$ \\
\hline $\begin{array}{l}\text { SeNPs-PP } \\
\text { fabric }\end{array}$ & & 47.39 & 23.45 & 17.09 & 29.02 & 36.08 & 4.34 \\
\hline
\end{tabular}

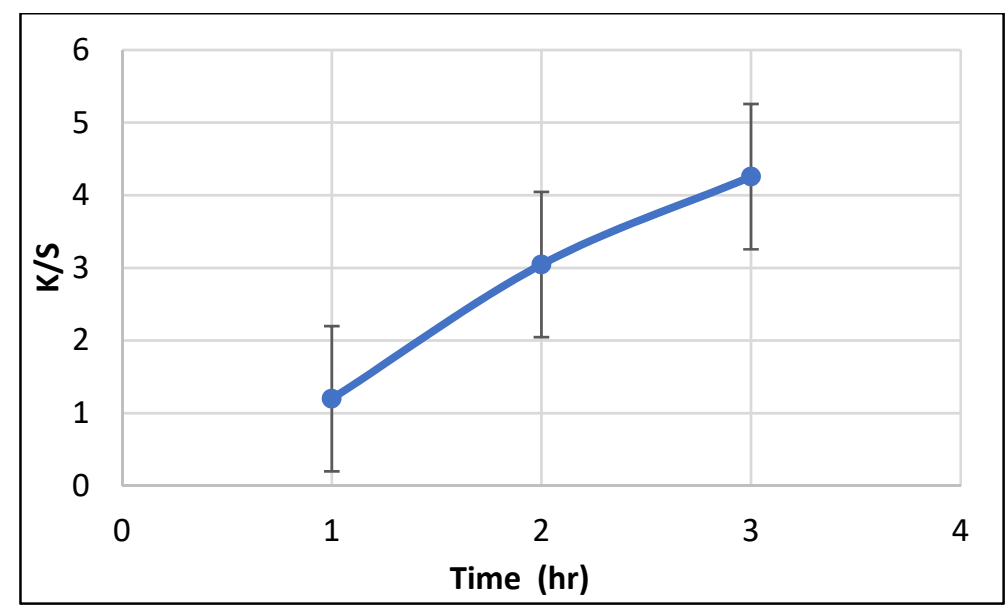

Figure 7. Effect of treatment time on color strength $(\mathrm{K} / \mathrm{S})$.

Effect of Treatment Temperature on Color Strength (K/S)

Figure 8 shows the relationship between treatment temperature and the color uptake (K/S) of the SeNPs-PP fabric with a (concentration of $50 \mathrm{mmol} / \mathrm{L}, \mathrm{L} . \mathrm{R}$ 1:50 and a treatment time of $3 \mathrm{~h}$ ). $\mathrm{K} / \mathrm{S}$ increased linearly with an increase in temperature from $70^{\circ} \mathrm{C}$ to $120^{\circ} \mathrm{C}$ and increased considerably at low temperatures until the color approached to an equilibrium point above $100^{\circ} \mathrm{C}$. The molecular structure opens, which facilitates the uptake of NPs as the temperature increases. Hence, a high K/S value is obtained. This can be attributed to an increase in temperature, which improves the macromolecular chains of PP. Moreover, 
large pores and/or channels suitable for NPs penetration and diffusion are formed. Hence, the optimum temperature was set at $100{ }^{\circ} \mathrm{C}$ [49-52].

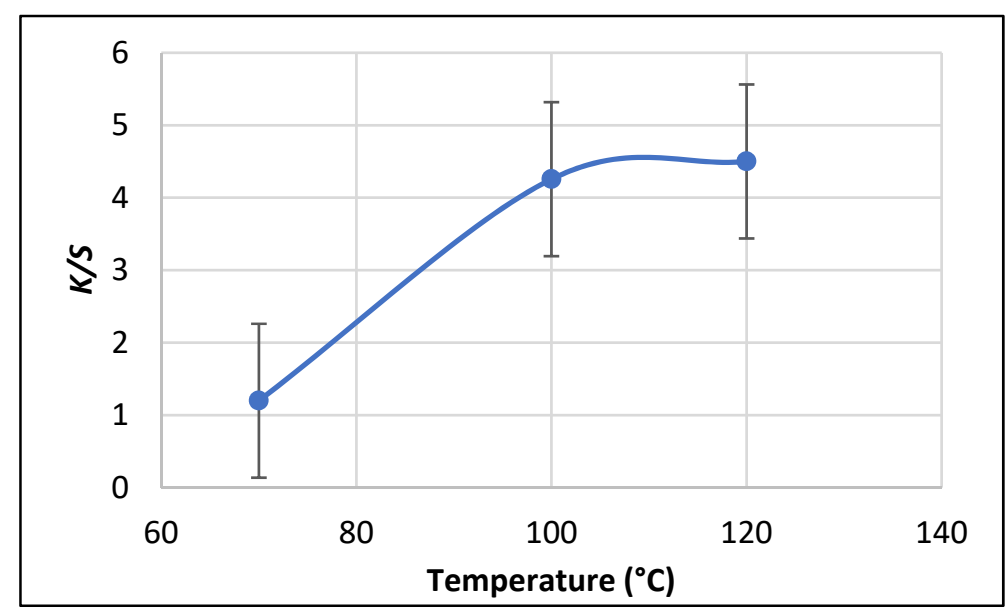

Figure 8. Effect of treatment temperature on color strength (K/S).

\subsubsection{Exhaustion of SeNPs into PP Fabric}

The treatment solution was sampled before and after treatment to measure the SeNPs exhaustion. Moreover, the absorbance of SeNPs solution was measured by using UV/VIS spectrophotometer-model: Alpha-1860. Figure 9 showed the absorbance of SeNPs concentration before and after exhaustion by PP fabric in the wavelength ranges from 200 to $700 \mathrm{~nm}$. The absorption spectrum of SeNPs-PP fabric before exhaustion shows a sharp absorption band at $263 \mathrm{~nm}$, indicating the presence of SeNPs. After exhaustion, remarkable decrease in the absorbance of the treatment solution can be attributed to the low ratio of SeNPs as it was absorbed by PP fabric.

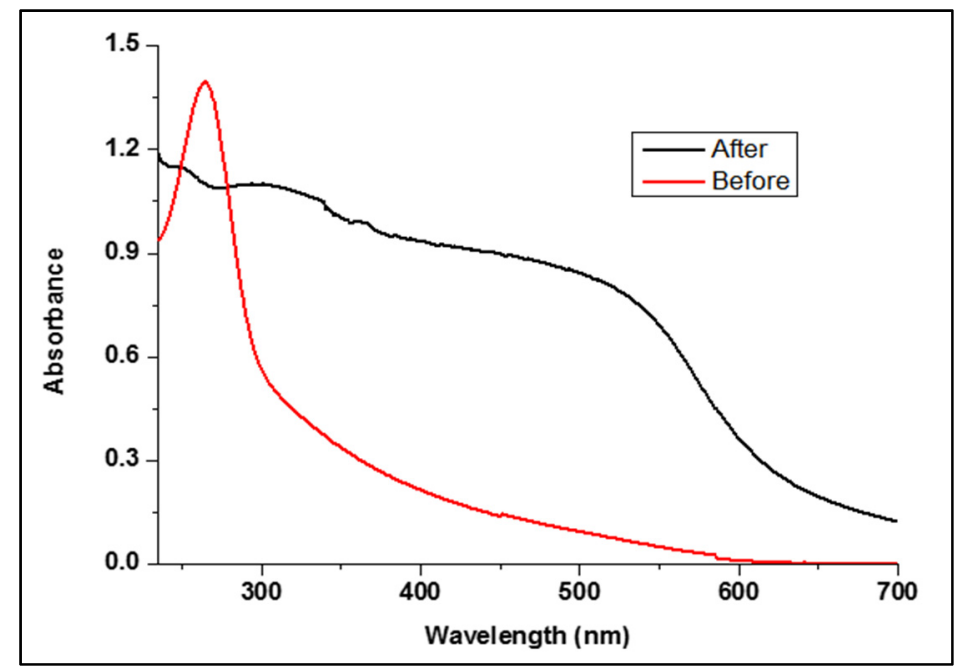

Figure 9. Absorbance of SeNPs before and after treatment.

\subsubsection{Physical Properties of SeNPs-PP Fabric}

The fastness of the SeNPs-PP fabric treated under optimum conditions was evaluated mainly in washing, rubbing, and lightfastness. In addition, the tensile strength (elongation and maximum force) was also evaluated. According to the results listed in Table 2, it can be concluded that there is a decrease in elongation and a little increase in maximum force of SeNPs-PP fabric without causing a significant damage to the structure of the yarn indicating no significant change between PP and SeNPs-PP fabrics. The washing and rubbing fastness were excellent, even after five washing cycles. Additionally, the light fastness of SeNPs-PP fabric was also found to be in the field of good to very good, this 
indicates that the fixation of SeNPs onto PP fabric may be attributed to the generation of metal chelates [53].

Table 2. Properties of the PP and SeNPs-PP fabrics under optimum conditions.

\begin{tabular}{|c|c|c|c|c|c|c|c|}
\hline \multirow{2}{*}{ Sample } & \multicolumn{2}{|c|}{ Wash Fastness } & \multicolumn{2}{|c|}{ Rubbing Fastness } & \multirow{2}{*}{$\begin{array}{c}\text { Light } \\
\text { Fastness }\end{array}$} & \multicolumn{2}{|c|}{ Tensile Strength } \\
\hline & St. & Alt. & Dry & Wet & & Force, $\mathrm{N}$ & Elongation, $\%$ \\
\hline PP fabric & - & - & - & - & - & 1090 & 30.80 \\
\hline SeNPs-PP fabric & 5 & 5 & 5 & $4-5$ & 5 & 1102 & 27.36 \\
\hline SeNPs-PP fabric after & & & & & & & \\
\hline $\begin{array}{l}5 \text { washing cycles } \\
\text { (durability test) }\end{array}$ & 5 & 5 & 5 & $4-5$ & 5 & - & - \\
\hline
\end{tabular}

\subsubsection{Cytotoxicity of the SeNPs-PP Fabric}

The cytotoxicity of the SeNPs-PP fabric was evaluated against healthy human cells (wi-38) by the MTT assay. The viability of cells and the cytotoxicity of SeNPs-PP fabric were evaluated against wi-38 cell lines. The viability of cells of SeNPs-PP fabric was $99.46 \%$ of that of negative control. Whereas over $70 \%$ is the mean relative cell viability [54]

\subsubsection{Antibacterial Activity of the SeNPs-PP Fabric}

Table 3 lists the antibacterial activity of the SeNPs-PP fabric using four bacterial strains, (Staphylococcus aureus and Bacillus cereus) as Gram-positive bacteria and (Escherichia coli and Pseudomonas aeruginosa) as Gram-negative bacteria. Tetracycline and ciprofloxacin were used as standard drugs. The results reveal that the SeNPs-PP fabric exhibits excellent antibacterial activity against Escherichia coli, Bacillus cereus, as well as Staphylococcus aureus and very good antibacterial activity against Pseudomonas aeruginosa, which is indicated by a clear zone diameter of bacterial colonies. The obtained results indicate the presence of broad-spectrum antibacterial activity. The mechanism of action of SeNPs on bacteria is still unclear. In this study, we suggest the following phenomena: (a) the release of ions along with physical interaction with the bacterial cell wall peptidoglycan layer damages the double-stranded structure of DNA. (b) the formation of reactive oxygen species and inhibition of DNA replication. (c)nanoparticles can be in better contact with bacterial or fungal cells than colloidal form [53].

Table 3. Clear zone (mm) of the PP and SeNPs-PP fabrics.

\begin{tabular}{ccccc}
\hline \multirow{2}{*}{ Substrate } & \multicolumn{4}{c}{$\begin{array}{c}\text { Antibacterial Activity } \\
\text { Diameter of Clear Zone (mm) }\end{array}$} \\
\cline { 2 - 5 } & $\begin{array}{c}\text { Staphylococcus } \\
\text { aureus } \\
(\mathbf{G +}\end{array}$ & $\begin{array}{c}\text { Bacillus cereus } \\
(\mathbf{G + )}\end{array}$ & $\begin{array}{c}\text { Escherichia coli } \\
\text { (G-) }\end{array}$ & $\begin{array}{c}\text { Pseudomonas } \\
\text { aeruginosa } \\
\text { (G-) }\end{array}$ \\
\hline Ciprofloxacin & 24 & 15 & 23 & 17 \\
Tetracycline & 21 & 14 & 20 & 15 \\
Blank & - & - & - & - \\
SeNPs-PP fabric & 20.9 & 22.7 & 23.2 & 11.3 \\
\hline
\end{tabular}

\subsubsection{UV-Protection Properties of the SeNPs-PP Fabric}

Table 4 lists the results of the UV light protection characterization. The SeNPs-PP fabric effectively blocked UV radiation; based on the AATCC test criteria: if UPF of any fabric is more than 40as the fabric is a UV-defensive material [55]. 
Table 4. UPF of the PP and SeNPs-PP fabrics.

\begin{tabular}{cccc}
\hline Sample & UVA & UVB & UPF Value \\
& $\mathbf{3 1 5 - 4 0 0 ~} \mathbf{~ m ~}$ & $\mathbf{2 9 0 - 3 1 5} \mathbf{~ n m}$ & 3.20 \\
Blank PP fabric & 35.89 & 29.49 & 920.19 \\
SeNPs-PP fabric & 0.11 & 0.11 & \\
\hline
\end{tabular}

\subsubsection{Electrical Conductivity Measurement}

The treatment of PP fabrics with SeNPs led to a slight increase in the electrical conductivity of PP fabrics. Samples treated with the optimum concentration of SeNPs showed EC value of $5.84 \times 10^{-11} \Omega^{-1} \mathrm{Cm}^{-1}$ compared to untreated fabric which had EC value of $1.06 \times 10^{-11} \Omega^{-1} \mathrm{~cm}^{-1}$.

\section{Conclusions}

In this paper, we propose a novel approach for coloring and incorporating new functionalities to PP fabrics via one-step process using SeNPs. PP fabrics were colored from light to dark orange depending on the treatment time and concentration of sodium hydrogen selenite. The obtained results show that the deposition of SeNPs into PP fabric is accompanied by a considerable improvement in UV-protection. The obtained colored fabrics effectively blocked UV radiations, providing excellent UV-protection. Additionally, the treated fabrics exhibited outstanding washing, rubbing and light fastness. Moreover, the colored PP fabric showed excellent antibacterial activity against Staphylococcus aureus, Bacillus cereus, and Escherichia coli and very good antibacterial activity against Pseudomonas aeruginosa compared with the standard drugs such as tetracycline and ciprofloxacin. The tensile strength of the colored fabrics increased slightly accompanied by a slight decrease in elongation. This novel, and economical approach can be employed in the industry for coloration and multifunctionalization of PP fabrics instead of traditional dyeing and finishing processes.

Author Contributions: Conceptualization, T.A. and S.A.A.; methodology, S.A.A.; software, S.A.A. validation, S.M.R., K.S.-A. and T.A.; formal analysis, K.S.-A.; investigation, S.M.R.; resources, S.M.R.; data curation, S.A.A.; writing —original draft preparation, S.A.A.; writing — review and editing, T.A. and M.R.P.; visualization, M.R.P.; supervision, T.A.; project administration, T.A. All authors have read and agreed to the published version of the manuscript.

Funding: This research received no external funding.

Institutional Review Board Statement: Not applicable.

Informed Consent Statement: Not applicable.

Data Availability Statement: The data presented in this study are available on request from the corresponding author.

Conflicts of Interest: The authors declare no conflict of interest.

\section{References}

1. Marković, D.; Tseng, H.-H.; Nunney, T.; Radoičić, M.; Ilic-Tomic, T.; Radetić, M. Novel antimicrobial nanocomposite based on polypropylene non-woven fabric, biopolymer alginate and copper oxides nanoparticles. Appl. Surf. Sci. 2020, 527, 146829. [CrossRef]

2. Gupta, D.; Khare, S.K.; Laha, A. Antimicrobial properties of natural dyes against Gram-negative bacteria. Color. Technol. 2004, 120, 167-171. [CrossRef]

3. Wang, Q.; Barnes, L.-M.; Maslakov, K.I.; Howell, C.A.; Illsley, M.J.; Dyer, P.; Savina, I.N. In situ synthesis of silver or selenium nanoparticles on cationized cellulose fabrics for antimicrobial application. Mater. Sci. Eng. C 2021, 121, 111859. [CrossRef]

4. Beyth, N.; Houri-Haddad, Y.; Domb, A.; Khan, W.; Hazan, R. Alternative Antimicrobial Approach: Nano-Antimicrobial Materials. Evid. Based Complement. Altern. Med. 2015, 2015, 246012. [CrossRef] [PubMed]

5. Abou Elmaaty, T.; Abdeldayem, S.; Elshafai, N. Simultaneous Thermochromic Pigment Printing and Se-NP Multifunctional Finishing of Cotton Fabrics for Smart Childrenswear. Cloth. Text. Res. J. 2020, 38, 182-195. [CrossRef] 
6. Abou Elmaaty, T.; Mostafa, S.; Nasr Eldin, S.; Elgamal, G.M. One Step Thermochromic Pigment Printing and Ag NPs Antibacterial Functional Finishing of Cotton and Cotton/PET Fabrics. Fibers Polym. 2018, 19, 2317-2323. [CrossRef]

7. Abou Elmaaty, T.; Abdelaziz, E.; Nasser, D.; Abdelfattah, K.; Elkadi, S.; El-Nagar, K.I. Microwave and nanotechnology advanced solutions to improve ecofriendly cotton's coloration and performance properties. Egypt. J. Chem. 2018, 61, 493-502. [CrossRef]

8. Abou Elmaaty, T.; Elnnagar, K.; Raouf, S.; Abdelfattah, K.; El-Kadi, S.; Abdelaziz, E. One-step green approach for functional printing and finishing of textiles using silver and gold NPs. RSC Adv. 2018, 8, 25546-25557. [CrossRef]

9. Abou Elmaaty, T.; Mandour, B. $\mathrm{ZnO}$ and $\mathrm{TiO}_{2}$ Nanoparticles as Textile Protecting Agents against UV Radiation: A Review. Asian J. Chem. Sci. 2018, 4, 1-14. [CrossRef]

10. Gold, K.; Slay, B.; Knackstedt, M.; Gaharwar, A.K. Antimicrobial Activity of Metal and Metal-Oxide Based Nanoparticles. Adv. Ther. 2018, 1, 1700033. [CrossRef]

11. Roy, A.; Bulut, O.; Some, S.; Mandal, A.K.; Yilmaz, M.D. Green synthesis of silver nanoparticles: Biomolecule-nanoparticle organizations targeting antimicrobial activity. RSC Adv. 2019, 9, 2673-2702. [CrossRef]

12. Dastjerdi, R.; Montazer, M. A review on the application of inorganic nano-structured materials in the modification of textiles: Focus on anti-microbial properties. Colloids Surf. B 2010, 79, 5-18. [CrossRef]

13. Simončič, B.; Klemenčič, D. Preparation and performance of silver as an antimicrobial agent for textiles: A review. Text. Res. J. 2015, 86, 210-223. [CrossRef]

14. Radetić, M. Functionalization of textile materials with silver nanoparticles. J. Mater. Sci. 2013, 48, 95-107. [CrossRef]

15. Radetić, M.; Marković, D. Nano-finishing of cellulose textile materials with copper and copper oxide nanoparticles. Cellulose 2019, 26, 8971-8991. [CrossRef]

16. Yip, J.; Liu, L.; Wong, K.-H.; Leung, P.H.M.; Yuen, C.-W.M.; Cheung, M.-C. Investigation of antifungal and antibacterial effects of fabric padded with highly stable selenium nanoparticles. J. Appl. Polym. Sci. 2014, 131. [CrossRef]

17. Biswas, D.P.; O’Brien-Simpson, N.M.; Reynolds, E.C.; O'Connor, A.J.; Tran, P.A. Comparative study of novel in situ decorated porous chitosan-selenium scaffolds and porous chitosan-silver scaffolds towards antimicrobial wound dressing application. J. Colloid Interface Sci. 2018, 515, 78-91. [CrossRef] [PubMed]

18. Yu, B.; Zhang, Y.; Zheng, W.; Fan, C.; Chen, T. Positive Surface Charge Enhances Selective Cellular Uptake and Anticancer Efficacy of Selenium Nanoparticles. Inorg. Chem. 2012, 51, 8956-8963. [CrossRef]

19. Forootanfar, H.; Adeli-Sardou, M.; Nikkhoo, M.; Mehrabani, M.; Amir-Heidari, B.; Shahverdi, A.R.; Shakibaie, M. Antioxidant and cytotoxic effect of biologically synthesized selenium nanoparticles in comparison to selenium dioxide. J. Trace Elem. Med. Biol. 2014, 28, 75-79. [CrossRef]

20. Shakibaie, M.; Forootanfar, H.; Golkari, Y.; Mohammadi-Khorsand, T.; Shakibaie, M.R. Anti-biofilm activity of biogenic selenium nanoparticles and selenium dioxide against clinical isolates of Staphylococcus aureus, Pseudomonas aeruginosa, and Proteus mirabilis. J. Trace Elem. Med. Biol. 2015, 29, 235-241. [CrossRef] [PubMed]

21. Hariharan, H.; Al-Harbi, N.; Karuppiah, P.; Rajaram, S.K. Microbial synthesis of selinium nanocomposite using Saccharomyces cerevisiae and its antimicrobial activity against pathogens causing nosocomial infection. Chalcog. Lett. 2012, 9, 509-515.

22. Shakibaie, M.; Salari Mohazab, N.; Ayatollahi Mousavi, S.A. Antifungal Activity of Selenium Nanoparticles Synthesized by Bacillus species Msh-1 against Aspergillus fumigatus and Candida albicans. Jundishapur J. Microbiol. 2015, 8, e26381. [CrossRef]

23. Beheshti, N.; Soflaei, S.; Shakibaie, M.; Yazdi, M.H.; Ghaffarifar, F.; Dalimi, A.; Shahverdi, A.R. Efficacy of biogenic selenium nanoparticles against Leishmania major: In vitro and in vivo studies. J. Trace Elem. Med. Biol. 2013, 27, 203-207. [CrossRef] [PubMed]

24. Gawish, S.M.; Mosleh, S.E.-S.; Ramadan, A. Review Improvement of Polypropylene Properties by Irradiation/Grafting and Other Modifications. Egypt. J. Chem. 2019, 62, 29-48. [CrossRef]

25. Gawish, S.; Ramadan, A.; Mosleh, S. Improvement of Polypropylene (PP) Dyeing by Modification Methods. Egypt. J. Chem. 2018, 62, 49-62. [CrossRef]

26. Tao, G.; Gong, A.; Lu, J.; Sue, H.-J.; Bergbreiter, D.E. Surface Functionalized Polypropylene: Synthesis, Characterization, and Adhesion Properties. Macromolecules 2001, 34, 7672-7679. [CrossRef]

27. Goddard, J.M.; Hotchkiss, J.H. Polymer surface modification for the attachment of bioactive compounds. Prog. Polym. Sci. 2007, 32, 698-725. [CrossRef]

28. Bandopadhay, D.; Tarafdar, A.; Panda, A.B.; Pramanik, P. Surface modification of low-density polyethylene films by a novel solution base chemical process. J. Appl. Polym. Sci. 2004, 92, 3046-3051. [CrossRef]

29. Perkas, N.; Shuster, M.; Amirian, G.; Koltypin, Y.; Gedanken, A. Sonochemical immobilization of silver nanoparticles on porous polypropylene. J. Polym. Sci. Part A Polym. Chem. 2008, 46, 1719-1729. [CrossRef]

30. Gawish, S.M.; Mosleh, S. Antimicrobial Polypropylene Loaded by Silver Nano Particles. Fibers Polym. 2020, 21, 19-23. [CrossRef]

31. Elmaaty, T.A.; Raouf, S.; Sayed-Ahmed, K. Novel One Step Printing and Functional Finishing of Wool Fabric Using Selenium Nanoparticles. Fibers Polym. 2020, 21, 1983-1991. [CrossRef]

32. Brandrup, J.; Immergut, E.H.; Grulke, E.A.; Abe, A.; Bloch, D.R. Polymer Handbook; Wiley: New York, NY, USA, 1999 ; p. 89.

33. Malhotra, S.; Jha, N.; Desai, K. A superficial synthesis of selenium nanospheres using wet chemical approach. Int. J. Nanotechnol. Appl. 2013, 3, 7-14.

34. American Association of Textile Chemists and Colorists. AATTCC 16A-1972: Colorfastness to Light: Carbon-arc Lamp; American Association of Textile Chemists and Colorists: Research Triangle Park, NC, USA, 1972. 
35. International Organization for Standardization. ISO 13934-1:1999: Tensile Properties of Fabrics; ISO: Vernier, Switzerland, 1999.

36. American Association of Textile Chemists and Colorists. AATTCC 61(2A)-1996: Colorfastness to Laundering; American Association of Textile Chemists and Colorists: Research Triangle Park, NC, USA, 1996.

37. American Association of Textile Chemists and Colorists. AATTCC 147-2004: Antimicrobial Activity Assessment of Textile Materials; American Association of Textile Chemists and Colorists: Research Triangle Park, NC, USA, 2004.

38. Vieira, A.; Stein, E.; Andreguetti, D.; Cebrián-Torrejón, G.; Domènech, A.; Colepicolo, P.; Da Costa Ferreira, A.M. “Sweet Chemistry": A Green Way for Obtaining Selenium Nanoparticles Active against Cancer Cells. J. Braz. Chem. Soc. 2017, 28, 2021-2027. [CrossRef]

39. Wang, S.; Ajji, A.; Guo, S.; Xiong, C. Preparation of Microporous Polypropylene/Titanium Dioxide Composite Membranes with Enhanced Electrolyte Uptake Capability via Melt Extruding and Stretching. Polymers 2017, 9, 110. [CrossRef]

40. Alagesan, V.; Venugopal, S. Green Synthesis of Selenium Nanoparticle Using Leaves Extract of Withania somnifera and Its Biological Applications and Photocatalytic Activities. BioNanoScience 2019, 9, 105-116. [CrossRef]

41. Satgurunathan, T.; Bhavan, P.; Komathi, S. Green synthesis of selenium nanoparticles from sodium selenite using garlic extract and its enrichment on Artemia nauplii to feed the fresh water prawn Macrobrachium rosenbergii post-larvae. Res. J. Chem. Environ. 2017, 21, 1-12.

42. El-Kheir, A.; El-Ghany, N.; Fahmy, M.; Aboras, S.; El-Gabry, L. Functional Finishing of Polyester Fabric Using Bentonite Nano-Particles. Egypt. J. Chem. 2019, 63. [CrossRef]

43. Arruebarrena de Báez, M.; Hendra, P.J.; Judkins, M. The Raman spectra of oriented isotactic polypropylene. Spectrochim. Acta Part A Mol. Spectrosc. 1995, 51, 2117. [CrossRef]

44. Martin, J.; Ponçot, M.; Hiver, J.M.; Bourson, P.; Dahoun, A. Real-time Raman spectroscopy measurements to study the uniaxial tension of isotactic polypropylene: A global overview of microstructural deformation mechanisms. J. Raman Spectrosc. 2013, 44, 776-784. [CrossRef]

45. Bashiri Rezaie, A.; Montazer, M.; Mahmoudi Rad, M. Low toxic antibacterial application with hydrophobic properties on polyester through facile and clean fabrication of nano copper with fatty acid. Mater. Sci. Eng. C 2019, 97, 177-187. [CrossRef]

46. Khalifa, M.E.; Abdel-Latif, E.; Gobouri, A.A. Disperse Dyes Based on 5-Arylazo-thiazol-2-ylcarbamoyl-thiophenes: Synthesis, Antimicrobial Activity and Their Application on Polyester. J. Heterocycl. Chem. 2015, 52, 674-680. [CrossRef]

47. Long, J.-J.; Ma, Y.-Q.; Zhao, J.-P. Investigations on the level dyeing of fabrics in supercritical carbon dioxide. J. Supercrit. Fluids 2011, 57, 80-86. [CrossRef]

48. Hou, A.; Dai, J. Kinetics of dyeing of polyester with CI Disperse Blue 79 in supercritical carbon dioxide. Coloration Technol. 2005, 121, 18-20. [CrossRef]

49. Al-Etaibi, A.M.; Alnassar, H.S.; El-Apasery, M.A. Dyeing of polyester with disperse dyes: Part 2. Synthesis and dyeing characteristics of some azo disperse dyes for polyester fabrics. Molecules 2016, 21, 855. [CrossRef]

50. Farizadeh, K.; Yazdanshenas, M.; Montazer, M.; Malek, R.; Rashidi, A. Kinetic studies of adsorption of madder on wool using various models. Text. Res. J. 2010, 80, 847-855. [CrossRef]

51. Kim, S.; Wairkar, Y.P.; Daniels, R.W.; DiAntonio, A. The novel endosomal membrane protein Ema interacts with the class C Vps-HOPS complex to promote endosomal maturation. J. Cell Biol. 2010, 188, 717-734. [CrossRef]

52. Miah, L.; Ferdous, N.; Azad, D. Textiles Material Dyeing with Supercritical Carbon Dioxide $\left(\mathrm{CO}_{2}\right)$ without using Water. Chem. Mater. Res. 2013, 3, 38-40.

53. Pandit, P.; Teli, M.D.; Therani Nadathur, G.; Maiti, S.; Singha, K.; Maity, S. Green synthesis of nanoparticle and its application on cotton fabric using Sterculia foetida fruit shell extract. J. Text. Eng. Fash. Technol. 2020, 6. [CrossRef]

54. Kangwansupamonkon, W.; Lauruengtana, V.; Surassmo, S.; Ruktanonchai, U. Antibacterial effect of apatite-coated titanium dioxide for textiles applications. Nanomed. Nanotechnol. Biol. Med. 2009, 5, 240-249. [CrossRef]

55. Mousa, M.A.; Khairy, M. Synthesis of nano-zinc oxide with different morphologies and its application on fabrics for UV protection and microbe-resistant defense clothing. Text. Res. J. 2020, 90, 2492-2503. [CrossRef] 